\title{
Diversidade Genética de Isolados de Rhizoctonia solani coletados em Feijão-caupi no Estado de Roraima
}

\author{
Aloísio Sartorato ${ }^{1}$, Kátia L. Nechet ${ }^{2} \&$ Bernardo A. Halfeld-Vieira ${ }^{2}$ \\ Embrapa Arroz e Feijão, Cx. Postal 179, CEP 75375-000, Santo Antônio de Goiás, GO, e-mail: sartorat@cnpaf.embrapa.br; \\ ${ }^{2}$ Embrapa Roraima, Cx. Postal 133, CEP 69301-970, Boa Vista, RR
}

(Aceito para publicação em 13/07/2006)

Autor para correspondência: Aloísio Sartorato

SARTORATO, A., NECHET, K.L. \& HALFED-VIEIRA, B.A. Diversidade genética de isolados de Rhizoctonia solani coletados em feijão-caupi no Estado de Roraima. Fitopatologia Brasileira 31:297-301. 2006.

\begin{abstract}
RESUMO
O feijão-caupi (Vigna unguiculata) é uma das principais fontes de proteína para a população de baixa renda, principalmente nas Regiões Norte e Nordeste do Brasil. Esta leguminosa é suscetível a várias doenças incluindo a mela ou murcha-da-teia-micélica, cujo agente causal é o fungo Rhizoctonia solani (teleomorfo: Thanatephorus cucumeris). Embora Rhizoctonia solani seja um agente causal de doença muito importante, no Brasil inexiste qualquer informação sobre as características de seus isolados associados ao feijão-caupi. O objetivo do presente estudo foi avaliar, utilizando-se das técnicas Random Amplified Polymorphic DNA (RAPD) e RFLP-ITS (Internal Transcribed Spacer), a diversidade genética de isolados de $R$. solani coletados de plantas de feijão-caupi oriundas da região de cerrado e de mata do Estado de Roraima. Pelos resultados obtidos pode-se concluir que existe diversidade genética em $R$.. solani coletada de feijão-caupi e que os dois métodos moleculares utilizados foram eficientes em avaliar a divergência genética deste patógeno.

Palavras-chave adicionais: RAPD, ITS, Vigna unguiculata, feijão de corda, feijão macassar, mela, murcha-dateia-micélica.

ABSTRACT

Genetic diversity of Rhizoctonia solani isolates collected from Cowpea in the State of Roraima

Cowpea (Vigna unguiculata) is one of the most important sources of protein for people with low incomes in Northern and Northeastern Brazil. Cowpea is susceptible to several diseases, including web blight caused by the fungus Rhizoctonia solani (teleomorph Thanatephorus cucumeris). Although $R$. solani is a very important disease agent, in Brazil there is no information on isolate characteristics when this fungus is associated with cowpea. The objective of this study was to evaluate, using Random Amplified Polymorphic DNA (RAPD) and RFLP-ITS (Internal Transcribed Spacer) techniques, the genetic diversity of $R$. solani isolates collected in the State of Roraima from cowpea cultivated under 'savannah' and 'forest' ecosystems. From the results it was possible to demonstrate genetic diversity among $R$. solani isolates and to prove that both molecular techniques used were efficient in evaluating it.
\end{abstract}

Additional keywords: RAPD, ITS, Vigna unguiculata, web blight.

O feijão-caupi [Vigna unguiculata (L.) Walp.], também conhecido como feijão macassar ou feijão de corda, apresenta alto conteúdo protéico e é pouco exigente em fertilidade do solo sendo um alimento básico para as populações das Regiões Norte e Nordeste do Brasil. Esta leguminosa, embora bem adaptada nestas regiões, é suscetível a várias doenças. Uma das mais importantes é a mela, também conhecida como murchada-teia-micélica, incitada pelo fungo Rhizoctonia solani J.G. Kühn [teleomorfo Thanatephorus cucumeris (A.B. Frank) Donk]. Nas condições do trópico úmido e em algumas regiões do semi-árido, a combinação de temperatura e umidade relativa elevada favorecem o desenvolvimento da doença que, em conseqüência, diminui a produtividade da cultura. Segundo Poltronieri et al. (1994), em alguns Estados da Região Norte esta doença pode ser a responsável por até $50 \%$ de perdas na cultura. $R$. solani representa um grupo economicamente importante e geneticamente diverso de patógenos de solo que ocorrem em várias espécies de plantas em todo o mundo (Cubeta \& Vilgalys, 1997). O critério de classificação de Rhizoctonia spp. está baseado na citomorfologia da hifa, morfologia da cultura, morfologia do teleomorfo, e o padrão de anastomose ou não de hifas (Sneh et al., 1991). Embora R. solani seja um organismo muito importante, no Brasil não existe qualquer informação sobre as características dos isolados de $R$. solani associados ao feijãocaupi.

Diferentes técnicas têm sido utilizadas com o intuito de estudar a diversidade genética de $R$. solani. Dentre elas, os marcadores RAPD (Random Amplified 
Polymorphic DNA) e a análise da região ITS (Internal Transcribed Spacer) do DNA ribossomal têm sido os mais empregados. Segundo White et al. (1990), a região espaçadora intergênica e o espaçador intergênico do rRNA nuclear evolui de uma forma bastante rápida quando comparado ao DNA nuclear e ao RNA mitocondrial e pode variar entre espécies de um gênero ou entre populações. O objetivo do presente estudo foi verificar a existência da diversidade genética entre isolados de $R$. solani coletados de plantas de feijão-caupi oriundas da região de cerrado e de mata do Estado de Roraima.

Dezenove isolados de $R$. solani foram obtidos de plantas de feijão-caupi exibindo sintomas da doença, em campos de produção no Estado de Roraima. Nove isolados foram oriundos do ecossistema de mata $(141 \mathrm{H}, 201 \mathrm{~A}, 201 \mathrm{~B}$, 201C, 208D, 220B, 220C, 220L e 220J), dez do ecossistema de cerrado $(154,200,200 \mathrm{~B}, 200 \mathrm{C}, 200 \mathrm{H}, 200 \mathrm{M}, 200 \mathrm{O}, 200 \mathrm{P}$, $200 \mathrm{~S}$ e $210 \mathrm{E})$ e quatro coletados de cultivares de feijoeiro comum [FE P01 (GO), FE 43 (GO), FE 44 (MG) e FE VAL (GO)] e oriundos da micoteca da Embrapa Arroz e Feijão foram cultivados em placas de Petri por três dias, em meio de BDA (Batata-Dextrose-Agar). Após este período, quatro a cinco discos de micélio, de cada isolado, com $0,7 \mathrm{~mm}$ de diâmetro, foram transferidos para Erlenmeyers de $125 \mathrm{~mL}$ contendo $50 \mathrm{~mL}$ do meio líquido de Batata + Dextrose (200 $\mathrm{g}$ de batata e $10 \mathrm{~g}$ de dextrose/litro de água) a fim de obterse o micélio do fungo. Em seguida, os Erlenmeyers foram colocados em uma mesa giratória com 120 RPM. Após quatro a cinco dias, o micélio foi coado em papel de filtro colocado em um frasco Kitasato, lavado duas a três vezes com água destilada estéril e armazenado a $-80^{\circ} \mathrm{C}$ (Carvalho \& Sartorato, 2002). A extração do DNA foi realizada conforme descrito por Raeder \& Broda (1985). O DNA de cada isolado foi avaliado pelas técnicas de RAPD (Random Amplified Polymorphic DNA) e de RFLF-ITS (Internal Transcribed Spacer).

$\mathrm{Na}$ amplificação do DNA de cada isolado, pelo método Random Amplified Polymorphic DNA (RAPD), realizada em um termociclador modelo PTC 100 da MJ Research (Waltham, MA, USA), foram utilizados os primers OP G04, G08, G13, G14, G15, G17, K10, L14, L17, L18, R03 e R13 (Operon Technologies, Inc., Alameda, CA). Cada reação de amplificação, com $25 \mu \mathrm{L}$, foi composta de $10 \mathrm{mM}$ Tris- $\mathrm{HCl}, \mathrm{pH} 8,0,50 \mathrm{mM} \mathrm{KCl}$, $2,8 \mathrm{mM} \mathrm{MgCl}_{2}, 0,1 \mathrm{mM}$ de cada dNTP, $0,4 \mu \mathrm{M}$ do primer, uma unidade de Taq DNA polimerase e $25 \mathrm{ng}$ de DNA. O programa de amplificação consistiu de 40 ciclos, sendo $15 \mathrm{~s}$ a $94{ }^{\circ} \mathrm{C}, 30 \mathrm{~s}$ a $35^{\circ} \mathrm{C}$ e $60 \mathrm{~s}$ a $72^{\circ} \mathrm{C}$, seguido de um ciclo final a $72{ }^{\circ} \mathrm{C}$ por $7 \mathrm{~min}$. Os produtos da reação foram separados em gel de agarose $1,2 \%$ contendo $0,2 \mu \mathrm{g}$ de brometo de etídio/mL imersos em tampão TBE $(90 \mathrm{mM}$ Tris-borato tampão, 1 mM EDTA, pH 8,0). Os fragmentos de DNA separados foram visualizados e fotografados sob luz UV e fotografadas com o sistema Eagle Eye II (Stratagene, La Jolla, CA, USA) (Sartorato et al., 2000). As bandas amplificadas foram anotadas segundo sua presença (1) ou sua ausência (0) para cada isolado do patógeno. A matriz de similaridade foi gerada utilizandose o coeficiente do quadrado da distância euclidiana e o método das médias aritméticas não ponderadas (UPGA). Em todos os cálculos foi utilizado o programa Statistic for Windows, versão 5.0.

As reações de PCR, pelo método RFLP-ITS, foram realizadas utilizando o par de primers ITS 1 ( 5 ' TCC GTA GGT GAA CCT GCG G 3') e ITS 4 (5' TCC TCC GCT TAT TGA TAT GC 3') (White et al., 1990). Cada reação de amplificação, com $50 \mu \mathrm{L}$, foi composta de $10 \mathrm{mM}$ Tris$\mathrm{HCl}, \mathrm{pH} 8,0,50 \mathrm{mM} \mathrm{KCl}, 2,5 \mathrm{mM} \mathrm{MgCl}, 0,1 \mathrm{mM}$ de cada dNTP (dATP, dGTP, dTTP e dCTP), 0,4 $\mu \mathrm{M}$ de cada primer ITS1 e ITS4, três unidades de Taq DNA polimerase (Invitrogen Corporation, São Paulo, Brasil) e 10 ng de DNA. O programa de amplificação consistiu de 40 ciclos, sendo $1 \mathrm{~min}$ a $94^{\circ} \mathrm{C}, 1 \mathrm{~min}$ a $50^{\circ} \mathrm{C}$ e $1 \min$ e $45 \mathrm{~s}$ a $72^{\circ} \mathrm{C}$, seguido de um ciclo final de extensão de $72{ }^{\circ} \mathrm{C}$, por $5 \mathrm{~min}$. $\mathrm{O}$ número de ciclos e a temperatura de anelamento foram ajustados para o caso específico dos primers utilizados. Os produtos da reação foram separados em gel de agarose $1,5 \%$ contendo $0,2 \mu \mathrm{g}$ de brometo de etídio/mL imersos em tampão TBE (90 mM Tris-borato tampão, $1 \mathrm{mM}$ EDTA, $\mathrm{pH}$ 8,0). O produto amplificado foi visualizado sob luz UV e fotografado com o sistema Eagle Eye II (Stratagene, La Jolla, CA, USA). Em seguida, $50 \mu \mathrm{L}$ do produto amplificado foram digeridos com as enzimas de restrição EcoR I, Hae III, Hind III, Hha I e Taq I. A digestão do DNA foi realizada segundo a indicação do fabricante das enzimas (Invitrogen Corporation, São Paulo, Brasil). Cada reação de restrição com $10 \mu \mathrm{L}$ consistiu de $1 \mu \mathrm{L}$ do tampão específico para cada enzima, 5 unidades da enzima, $3,5 \mu \mathrm{L}$ de água e $5 \mu \mathrm{L}$ de solução de DNA a 10 $\mathrm{ng} / \mu \mathrm{L}$. Com exceção da digestão com a enzima Taq I que utilizou a temperatura de $65{ }^{\circ} \mathrm{C}$ por $2 \mathrm{~h}$; para as demais enzimas foi utilizada a temperatura de $37^{\circ} \mathrm{C}$ durante toda a noite. Após estes períodos, nova eletroforese em gel de agarose a $2 \%$ contendo $0,2 \mu \mathrm{g}$ de brometo de etídio/ $\mathrm{mL}$ foi realizada. De forma análoga ao realizado para o experimento de RAPD, as bandas amplificadas foram anotadas segundo sua presença (1) ou sua ausência (0) para cada isolado do patógeno. A matriz de similaridade foi gerada utilizando a mesma metodologia descrita para a técnica de RAPD. Em todos os cálculos foi utilizado o programa Statistics for Windows, versão 5.0.

Independentemente do método molecular utilizado, os isolados foram divididos em dois grandes grupos (Figura 1). Com exceção do isolado $141 \mathrm{H}$, todos os isolados coletados no ecossistema mata foram reunidos em um único grupo indicando que os mesmos são geneticamente semelhantes entre si (menos divergentes). Resultados similares foram obtidos por Meinhardt et al. (2002) estudando isolados de R. solani oriundos do feijoeiro comum. Com relação aos isolados coletados no ecossistema cerrado observou-se que quatro deles (200P, 200B, 210E e 200M) foram reunidos no grupo 1 e cinco 

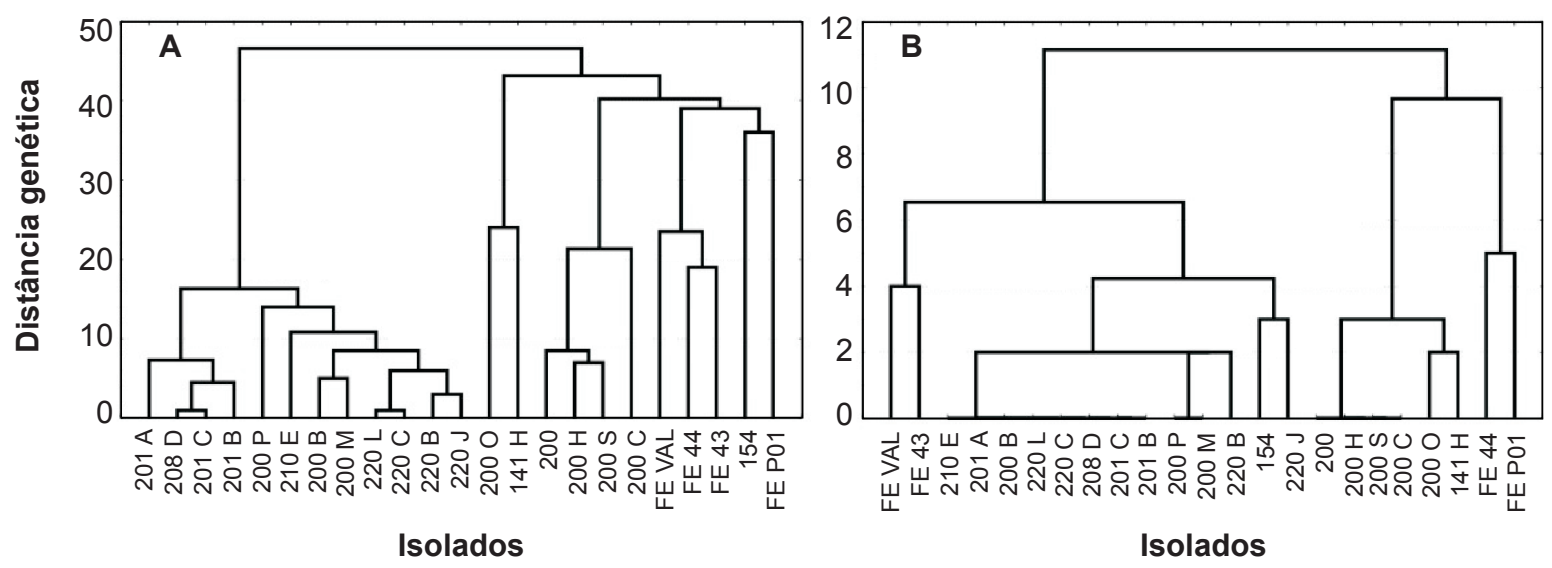

FIG. 1 - Dendrograma de 23 isolados de Rhizoctonia solani pelos métodos (a) Random Amplified Polymorphic DNA (RAPD) (primers OP G04, G08, G13, G14, G15, G17, K10, L14, L17, L18, R03 e R13) e (b) RFLP-ITS (Internal Transcribed Spacer) - 5.8S do rDNA (primers ITS 1 e ITS 4) após digestão com as enzimas EcoR I, Hae III, Hha I e Taq I.

$(200,200 \mathrm{H}, 200 \mathrm{~S}, 200 \mathrm{C}$ e $200 \mathrm{O})$ no grupo 2. Estes dados indicam que os isolados coletados no ecossistema cerrado são mais divergentes entre si que os isolados coletados no ecossistema mata. A existência da divergência genética entre isolados/populações do fungo $R$. solani já tinha sido observada (Liu \& Sinclair, 1992; Gomes et al., 2003). $\mathrm{O}$ isolado 154, oriundo do ecossistema cerrado, quando avaliado pelo método de RAPD foi reunido entre os isolados do grupo 2; entretanto, quando foi utilizado o método de RFLP-ITS, com digestão enzimática, o isolado 154 reuniu-se entre os isolados do grupo 1, composto pela grande maioria dos isolados do ecossistema mata. Segundo Nechet \& Halfeld-Vieira (2005), ele difere dos demais por ser binucleado não tendo sido, ainda, determinado a que grupo de anastomose pertence. Os isolados coletados de feijoeiro comum FE VAL, FE 43, FE 44 e FE P01, quando avaliados pelo método RAPD reuniram-se no grupo 2 , mostrando-se semelhantes a alguns isolados coletados no ecossistema cerrado. No entanto, quando avaliados pelo método RFLP-ITS com digestão enzimática, os isolados FE VAL e FE 43 mostraram-se mais próximos aos isolados do ecossistema mata (Figura 1). Os outros dois isolados do feijoeiro comum (FE 44 e FE P01), quando avaliados por este método continuaram semelhantes aos isolados coletados no cerrado. Liu \& Sinclair (1992) afirmaram que $R$. solani é altamente variável, o que explica a divergência encontrada entre os isolados oriundos do ecossistema cerrado. As distâncias genéticas com base nos dados da amplificação pela técnica de RAPD e de RFLP-ITS estão apresentadas na Tabela 1. Pela técnica da análise da região ITS do DNA ribossomal, 35 pares de isolados apresentaram um índice de similaridade de $100 \%$, demonstrando uma alta identidade genética entre eles. Estudos complementares indicaram que os isolados de $R$. solani utilizados neste estudo pertencem ao grupo de anastomose GA1-IA, com exceção do isolado 154 (Nechet \& Halfeld-Vieira, 2005).
Segundo Gomes et al. (2003), a região completa (ITS-rDNA) do fungo $R$. solani coletado de feijoeiro comum cultivado no ecossistema cerrado apresentou um tamanho de aproximadamente $640 \mathrm{pb}$. Entretanto, a região ITS dos isolados analisados no presente estudo apresentou um tamanho de aproximadamente $700 \mathrm{pb}$, inclusive para os quatro isolados oriundos do feijoeiro comum. Resultado semelhante foi obtido por Meinhardt et al. (2002) utilizando os mesmos pares de primers empregados neste estudo. Essa diferença no número de pares de base encontrado entre estes estudos é devida à região ITS explorada pelos primers utilizados (ITS $1 \mathrm{e}$ ITS 4). Não foram observados sítios de restrição quando os isolados foram submetidos à enzima Hind III. Para as demais enzimas empregadas foram observados dois sítios de restrição. A variação no tamanho dos fragmentos resultantes da restrição com diferentes enzimas sugerem que algum evento de inserção ou deleção de pares de base estão envolvidos na evolução deste fungo (Liu \& Sinclair, 1992). Segundo estes autores, inserções e/ou deleções além de mutações parecem ser comuns em $R$. solani.

O conhecimento da diversidade genética do patógeno pode ser de grande valia em um programa de melhoramento genético, uma vez que pode auxiliar o melhorista na identificação de novas fontes de resistência. No entanto, a existência de dois grupos geneticamente distintos em áreas próximas, como o encontrado no presente estudo, possibilita a oportunidade de trocas genéticas entre eles podendo levar a um aumento na variabilidade genética dos isolados o que pode refletir em um aumento na patogenicidade dos mesmos, o que é de grande importância do ponto de vista do patossistema.

Pelos resultados obtidos pode-se concluir que existe diversidade genética entre os isolados de $R$. solani coletados de plantas de feijão-caupi e que as duas técnicas moleculares utilizadas foram eficientes em avaliar esta diversidade. 
TABELA 1 - Distância genética (\%) entre pares de isolados de Rhizoctonia solani após amplificação com os primers ITS 1 e ITS 4 e digestão dos produtos com os enzimas EcoR I, Hae III, Hha I e Taq I (parte superior da tabela) e amplificação com os primers OP G04, G08, G13, G14, G15, G17, K10, L14, L17, L18, R03 e R13 (parte inferior da tabela)

\begin{tabular}{|c|c|c|c|c|c|c|c|c|c|c|c|c|c|c|c|c|c|c|c|c|c|c|c|}
\hline Isol $^{1}$ & $1^{2}$ & 2 & 3 & 4 & 5 & 6 & 7 & 8 & 9 & 10 & 11 & 12 & 13 & 14 & 15 & 16 & 17 & 18 & 19 & 20 & 21 & 22 & 23 \\
\hline 1 & & 10 & 11 & 12 & 12 & 8 & 12 & 12 & 12 & 8 & 10 & 12 & 5 & 12 & 12 & 12 & 12 & 8 & 12 & 12 & 8 & 8 & 12 \\
\hline 2 & 24 & & 11 & 10 & 10 & 2 & 8 & 8 & 8 & 4 & 12 & 10 & 11 & 10 & 10 & 10 & 10 & 4 & 10 & 10 & 4 & 4 & 10 \\
\hline 3 & 29 & 27 & & 7 & 3 & 11 & 3 & 5 & 5 & 11 & 9 & 5 & 8 & 5 & 5 & 5 & 5 & 11 & 5 & 5 & 11 & 11 & 5 \\
\hline 4 & 26 & 22 & 29 & & 4 & 12 & 8 & 6 & 6 & 12 & 4 & 6 & 9 & 6 & 6 & 6 & 6 & 12 & 6 & 6 & 12 & 12 & 6 \\
\hline 5 & 29 & 29 & 2 & 31 & & 12 & 4 & 2 & 2 & 12 & 8 & 2 & 9 & 2 & 2 & 2 & 2 & 12 & 2 & 2 & 12 & 12 & 2 \\
\hline 6 & 25 & 9 & 30 & 29 & 30 & & 10 & 10 & 10 & 2 & 10 & 12 & 11 & 12 & 12 & 12 & 12 & 2 & 12 & 12 & 2 & 2 & 12 \\
\hline 7 & 23 & 23 & 32 & 25 & 32 & 24 & & 2 & 2 & 12 & 10 & 4 & 9 & 4 & 4 & 4 & 4 & 12 & 4 & 4 & 12 & 12 & 4 \\
\hline 8 & 26 & 26 & 5 & 28 & 5 & 27 & 29 & & 0 & 12 & 8 & 2 & 9 & 2 & 2 & 2 & 2 & 12 & 2 & 2 & 12 & 12 & 2 \\
\hline 9 & 29 & 29 & 6 & 31 & 6 & 30 & 30 & 3 & & 12 & 8 & 2 & 9 & 2 & 2 & 2 & 2 & 12 & 2 & 2 & 12 & 12 & 2 \\
\hline 10 & 27 & 23 & 34 & 21 & 36 & 28 & 22 & 33 & 36 & & 10 & 12 & 11 & 12 & 12 & 12 & 12 & 0 & 12 & 12 & 0 & 0 & 12 \\
\hline 11 & 20 & 16 & 21 & 12 & 23 & 21 & 21 & 20 & 23 & 19 & & 6 & 9 & 6 & 6 & 6 & 6 & 10 & 6 & 6 & 10 & 10 & 6 \\
\hline 12 & 25 & 27 & 14 & 27 & 14 & 28 & 28 & 11 & 14 & 32 & 19 & & 9 & 0 & 0 & 0 & 0 & 12 & 0 & 0 & 12 & 12 & 0 \\
\hline 13 & 21 & 21 & 28 & 7 & 30 & 26 & 24 & 27 & 30 & 24 & 9 & 24 & & 9 & 9 & 9 & 9 & 11 & 9 & 9 & 11 & 11 & 9 \\
\hline 14 & 28 & 30 & 11 & 30 & 11 & 29 & 31 & 10 & 13 & 35 & 22 & 3 & 27 & & 0 & 0 & 0 & 12 & 0 & 0 & 12 & 12 & 0 \\
\hline 15 & 29 & 29 & 10 & 29 & 10 & 30 & 32 & 9 & 12 & 36 & 23 & 4 & 28 & 1 & & 0 & 0 & 12 & 0 & 0 & 12 & 12 & 0 \\
\hline 16 & 27 & 29 & 6 & 29 & 6 & 28 & 28 & 7 & 8 & 34 & 21 & 10 & 28 & 9 & 10 & & 0 & 12 & 0 & 0 & 12 & 12 & 0 \\
\hline 17 & 26 & 28 & 5 & 30 & 5 & 27 & 27 & 6 & 7 & 33 & 20 & 11 & 27 & 10 & 11 & 1 & & 12 & 0 & 0 & 12 & 12 & 0 \\
\hline 18 & 29 & 27 & 34 & 23 & 34 & 28 & 24 & 31 & 32 & 14 & 23 & 32 & 26 & 33 & 34 & 32 & 31 & & 12 & 12 & 0 & 0 & 12 \\
\hline 19 & 27 & 27 & 2 & 29 & 2 & 28 & 30 & 3 & 4 & 34 & 21 & 12 & 28 & 11 & 10 & 4 & 3 & 32 & & 0 & 12 & 12 & 0 \\
\hline 20 & 29 & 27 & 10 & 29 & 10 & 28 & 32 & 9 & 12 & 36 & 23 & 6 & 28 & 3 & 2 & 10 & 11 & 34 & 10 & & 12 & 12 & 0 \\
\hline 21 & 25 & 25 & 34 & 21 & 34 & 28 & 24 & 31 & 32 & 12 & 21 & 30 & 24 & 33 & 34 & 32 & 31 & 4 & 32 & 34 & & 0 & 12 \\
\hline 22 & 23 & 23 & 30 & 23 & 30 & 26 & 22 & 27 & 28 & 14 & 19 & 26 & 22 & 29 & 30 & 28 & 27 & 8 & 28 & 30 & 4 & & 12 \\
\hline 23 & 22 & 24 & 9 & 26 & 9 & 25 & 23 & 8 & 9 & 29 & 16 & 9 & 23 & 12 & 13 & 7 & 6 & 29 & 7 & 13 & 27 & 23 & \\
\hline
\end{tabular}

${ }^{1}$ Isol=Isolado; ${ }^{2} 1=\mathrm{FE}$ P01, $2=141 \mathrm{H}, 3=220 \mathrm{~J}, 4=\mathrm{FE} 43,5=220 \mathrm{~B}, 6=200 \mathrm{O}, 7=154,8=200 \mathrm{M}, 9=200 \mathrm{P}, 10=200 \mathrm{C}, 11=\mathrm{FE}$ VAL, 12=201B, 13=FE 44, 14=201C, 15=208D, 16=220C, 17=220L, 18=200S, 19=200B, 20=201A, $21=200 \mathrm{H}, 22=200$ e $23=210$ E.

\section{REFERÊNCIAS BIBLIOGRÁFICAS}

CARVALHO, F.A. \& SARTORATO, A. Meio líquido para produção de micélio de Phaeoisariopsis griseola e Colletotrichum lindemuthianum. Anais, $7^{\circ}$ Congresso Nacional de Pesquisa de Feijão, Viçosa MG. 2002. pp. 120-124.

CUBETA, M.A. \& VILGALYS, R. Population Biology of the Rhizoctonia solani Complex. Phytopathology 87:480-484. 1997.

GOMES, M.V.L., BRESEGHELlO, L., SILVA, W.S. \& PETROFEZA, S. Diversidade genética em populações de Rhizoctonia solani isolados de feijoeiro em sistema de produção irrigado no cerrado. Resumos, $49^{\circ}$ Congresso Brasileiro de Genética, Águas de Lindóia SP. 2003. p. 1149.

LIU, Z.L. \& SINCLAIR, J.B. Genetic Diversity of Rhizoctonia solani anastomosis group 2. Phytopathology 82:778-787. 1992.

MEINHARDT, L.W., WULFF, N.A., BELLATO, C.M. \& TSAI, S.M. Genetic analyses of Rhizoctonia solani isolates from Phaseolus vulgaris grown in the Atlantic rainforest region of São Paulo, Brazil. Fitopatologia Brasileira 27:259-267. 2002.

NECHET, K.L. \& HALFELD-VIEIRA, B.A. Caracterização de isolados de Rhizoctonia spp., associados a mela do feijão-caupi, coletados em Roraima. Fitopatologia Brasileira 30(Supl.):87. 2005. 
POLTRONIERI, L.S., TRINDADE, D.R. \& SILVA, J.F.A.F. Principais doenças do feijão-caupi (Vigna unguiculata (L.) Walp.) no Pará e recomendações de controle. Belém PA. Embrapa CPATU. 1994. (Documentos, 75).

RAEDER, U. \& BRODA, P. Rapid preparation of DNA from filamentous fungi. Letters in Applied Microbiology 1:17-20. 1985.

SARTORATO, A., NIETSCHE, S., BARROS, E.G. \& MOREIRA, M.A. RAPD and SCAR markers linked to resistance gene to angular leaf spot in common beans. Fitopatologia Brasileira 25:637-642. 2000.

SNEH, B., BURPEE, L. \& OGOSHI, A. Identification of Rhizoctonia species. St. Paul MN. APS Press. 1991.

WHITE, T.J., BRUNS, T., LEE, S. \& TAYLOR, J.Amplification and direct sequencing of fungal ribosomal RNA genes for phylogenetics. In: Innis, M.A., Gelfand, D.H., Sninsky, J.J. \& White, T.L. (Eds.) PCR Protocols: A Guide to Methods and Applications. New York. Academic Press. 1990. pp. 315-322. 